\title{
PERAN PERGURUAN TINGGI AGAMA ISLAM NEGERI (PTAIN) DALAM MEMASUKI ERA KOMPETISI GLOBAL
}

\section{Oleh: Abdul Ghofir}

\begin{abstract}
Seiring dengan perjalanan waktu, nampaknya misi dakwah ini tidak lagi bisa dipertahankan, karena tidak sesuai dengan perkembangan dan tuntutan jaman. Disamping juga, misi dakwah ini ternyata tidak mempunyai malma yang signifikankepada masyarakat sekitar. Artinya, dengan keberadaan IAIN (dengan fakultas cabangnya) keadaan masyarakat sekitar tidak serta merta menjadi lebih berkualitas, baik secara sosial, moral dan spiritual. Bahkan di beberapa daerah, leberadaan IAIN tidak memberikan resonansi yang signifikan terhadap masyarakat sekitarnya. Ada dan tidak adanya IAIN, tidak memberikan dampak langsung maupuntidak langsung terhadap masyarakat. Demikian juga sebaliknya, beberapa daerah yang kebetulan tidak ditempati IAIN (fakultas cabangnya) bukan berarti secara moral dan spiritual lebih jelek dari yang ditempati IAIN.
\end{abstract}

\section{Kata Kunci: Peran, PTI, Kompetisi, Global}

\section{A. Pengantar}

Secara historis, perguruan tinggi agama Islam (IAIN beserta fakultas cabangnya) yang didirikan secara terpencar-pencar di berbagai daerah, mempunyai misi dakwah. Sebagai lembaga yang mengemban misi dakwah, maka terkesan keberadaannya sekedar memenuhi selera "pasar dakwah", sehingga keilmuan yang dikembangkan lebih berorientasi pada "bekal" dakwah.

Seiring dengan perjalanan waktu, nampalnya misi dakwah ini tidak lagi bisa dipertahankan, karena tidak sesuai dengan perkembangan dan tuntutan jaman. Disamping juga, misi dakwah ini ternyata tidak mempunyai makna yang signifikan kepada masyarakat sekitar. Artinya, dengan keberadaan IAIN (dengan fakultas cabangnya) keadaan masyarakat sekitar tidak serta merta menjadi lebih berkualitas, baik secara sosial, moral dan spiritual. Bahkan di beberapa daerah, keberadaan IAIN tidak memberikan resonansi yang signifikan terhadap masyarakat sekitarnya. Ada dan tidak adanya IAIN, tidak memberikan dampak langsung maupun tidak langsung terhadap masyarakat. Demikian 
juga sebaliknya, beberapa daerah yang kebetulan tidak ditempati IAIN (fakultas cabangnya) bukan berarti secara moral dan spiritual lebih jelek dari yang ditempati IAIN.

Kondisi tersebut menyadarkan IAIN melakukan reorientasi keilnnuan, dengan tidak hanya sekedar misi dakwah, tetapi kemudianberkembang menjadi lembaga ilmiah yang berusaha untuk ikut serta mencerdaskan kehidupan bangsa bersama-sama perguruan tinggi umum lainnya. Hal ini ditandai dengan dibukanya beberapa jurusan umum pada IAIN, mulai pada tahun 70-an - 80an, kemudian berhenti sejenak pada tahun 90-an, dan dibuka kembali akhirakhir ini bersamaan dengan pisahnya fakultas cabang menjadi STAIN, dan berubahnya beberapa IAIN dan STAIN menjadi Universitas Islam Negeri (UIN). Kondisi ini memang menimbulkan kontroversi, dimana satu pihak menganggap bahwa, pembukaan jurusan umum ini merupakan konsekuensi logis dari realitas sosial yang menuntut ahli umum yang "ngerti" agama, di pihak lain mengangap bahwa, PTAIN (UIN, IAIN dan STAIN) telah keluar dari basic keilmuannya. Terlepas dari perdebatan itu, ternyata PTAIN lebih memilih alternatif yang pertama.

Namun demikian, ternyata jurusan-jurusan umum yang dibuka itu lebih bersifat praktis-pragmatis, sekedar untuk memenuhi kebutuhan guru di madrasah atau kebutuhan tenaga trampil pada berbagai lembaga yang berlebel Islam, sehingga tidak banyak dari lulusan jurusan umum PTAIN itu yang dapat berkiprah dalam panggung politik dan ekonomi secara nasional. Akibatnya, banyak kebijakan-kebijakan politik dan ekonomi yang lepas dari perhatian PTAIN, karena tidak signifikannya alumni yang ikut bermain di dalamnya.

Kondisi tersebut betul-betul terasa dampaknya sekarang ini. Ketika bangsa Indonesia mengalami krisis multi dimensional, yang bersumber dari persoalan politik dan ekonomi, ternyata tidak banyak kontribusi yang bisa diberikan oleh PTAIN (beserta alumninya) dalam mengatasi masalah bangsa yang berlarut-larut ini. Mereka yang dari jurusan umum juga tidak banyak kon ribusinya, apalagi yang dari junusan agama, karena tidak ada "bekal" untuk itu. Akibatnya, kita hanya menjadi kelompok marginal dan menjadi penonton dalam penggung sejarah ekonomi-politik bangsa yang carut-marut ini. Sebagai penonton, ternyata kita juga tidak nyaman, karena para pemainnya banyak yang melakukan tindakan kasar, dengan saling menendang "tanpa adanya bola". Hal inilah yang sebenarnya harus menjadi perhatian kita, sebagai orang yang meng."infaqkan" diri di lingkungan PTAIN, untuk melakukan reorientasi 
keilmuan dan pengembangan wawasan, agar kita dapat bermain dalam panggung sejarah kehidupan.

\section{B. Reorientasi Keilmuan di PTAIN}

Reorientasi keilmuan dan wawasan di lingkungan PTAIN akan lebih tepat kalau kita tanamkan sejak awal kepada mahasiswa. Secara institusionalakademis, reorientasi yang dapat dilakukan oleh pimpinan PTAIN bukan berarti harus membuka jurusan umum sebanyak-banyaknya, tetapi yang dapat dilakukan adalah memberikan bekal tambahan kepada mahasiswa., mengenai berbagai issue yang relevan untuk dikembangkan dalam bingkai akademis. Misalnya, mengenai issue-isue ekonomi, politik, sosial, budaya, dan pertahanan keamanan yang dapat kita "titipkan" melalui berbagai bidang mata kuliah yang ada. Ini bukan berarti PTAIN akan meninggalkan "khittahnya" sebagai pengembang keilmuan agama, tetapi merupakan konsekuensi logis dari realitas sosial yang menuntut peran-peran strategis PTAIN lebih maksimal untuk ikut serta dalam menyelesaikan krisis multi dimensional seperti sekarang ini. Sebab menurut prediksi saya, krisis ini nampaknya tidak begitu saja mudah berakhir, tetapi mungkin akan menggelinding terus -meskipun tidak seperti menggelindingnya bola salju-, karena ternyata tatanan birokrasi kita masih rentan untuk menerima berbagai hambatan dan tantangan politik, ekonomi, sosial, dan budaya. Ini memberikan implikasi bahwa, PTAIN belum terlambat untuk menyiapkan tenaga-tenaga ahli yang mampu menduduki posisi-posisi strategis dan mampu memberikan sumbangan pemikiran dalam menghadapi krisis multi dimensional.

Saya sepakat dengan apa yang disampaikan oleh Maskuri Abdillah (1997) bahwa, "pasar kerja" alumni PTAIN seharusnya tidak terbatas pada sektor-sektor "informal" semacam guru agama, guru ngaji, takmir masjid, juru dakwah, dan pengurus majlis taklim, tetapi juga dapat memasuki semua jalur formal dan sektor-sektor moderen, asal disiapkan dengan sungguh-sungguh. Sebab keberhasilan alumni, juga menentukan kebesaran perguruan tingginya. Hipotesis tentatifnya, semakin banyak alumni yang menduduki jabatan strategis semakin bergengsilah perguruan tinggi tersebut.

Sejalan dengan pemikiran Maskuri Abdillah, Dawam Rahardjo (1992), juga menawarkan beberapa profesi alternatif untuk mengisi elit strategis yang perlu dipikirkan -dan bisa disiapkan oleh PTAIN- yaitu: (1) negarawan dan politisi, (2) pemimpin masyarakat, (3) intelektual bebas, (4) peneliti sosialkeagamaan, (5) berbagai jenis tenaga professional, (6) manajer, baik untuk perusahaan maupun lembaga-lembaga lainnya, (7) seniman-budayawan, dan 
(8) wartawan atau publicist. Namun demikian, menurumya, di lapangan, alumni PTAIN sering kurang berani menghadapi tantangan, apalagi merebut pasar dalam persaingan. Akibatnya, alumni PTAN sering ketinggalan terus dalam even-even penting di republik ini, sehinga seakan-akan kalah sebelum bertanding. Mungkin ini, menurut hemat saya, merupakan refleksi dari sikap ikhlas dan nrimo ing pandum sebagai sebuah perwujudan dari adagium yang telah lama mengakar di lingkungan PTAN.

Untuk itu, kita perlu melakukan rekonstruksi terhadap makna ikhlas dan nrimo ing pandum. Artinya, dalam menghadapi realitas sosial, politik, dan ekonomi, kita tidak bisa hanya menangkap makna ikhlas dan nrimo ing pandum secara harfiah, tetapi harus tetap diletakkan dalam kerangka profesionalisme, yaitu do the right thing and do it right. Keikhlasan dan nrimo ing pandum akan memberi makna yang substansial, kalau sikap professionalisme menjadi acuan dalam menjalani aktifitas hidup, sehingga bekerja dan berkarya tidak sekedar apa adanya (yang penting ikhlas) tetapi betul-betul berkualitas, rasional dan dapat dipertanggungjawabkan. Sebab, sejarah telah mencatat dan mengabarkan kepada kita bahwa, keikhlasan dan nrimo ing pandum tidak menyelesaikan masalah, tetapi justeru akan memperkeruh masalah, kalau tidak dibingkai dengan profesionalisme yang tinggi. Untuk itu, sinergi antara ikhlas, nrimo ing pandum dan profesionalisme harus tetap dikembangkan di lingkungan PTAIN.

Pengembangan profesionalisme yang dibingkai dengan nilai keikhlasan ini bukan berarti menafikan peran-peran strategis para funding father yang telah terbangun selama ini, dimana PTAIN didirikan dengan nilai keikhlasan yang tinggi, tetapi lebih merupakan panggilan nurani untuk memberikan kontribusi yang lebih optimal dalam kehidupan berbangsa dan bernegara. Sebab tantangan kehidupan kita semakin keras dan semakin menyiksa, terutama tantangan pekerjaan dan jabatan. Hanya karena dua hal tersebut, banyak orang yang tega mengkhianati dirinya dan sahabat karibnya yang telah lama dijalin, demi untuk memperoleh prestasi dan prestise. Kondisi inilah yang harus kita sadari bersama bahwa, masih banyak peran dan tindakan strategis yang bisa kita lakukan dalam menghadapi tantangan globalisasi ini, dari sekedar rebutan "kue" reformasi.

Sebagai civitas akademika PTAIN, peran dan tindakan strategis yang bisa dilakukan, secara praktis-pragmatis, misalnya: (1) sebagai pelopor pembaharuan (agent of change), dimana PTAIN diharapkan mampu memberikan sumbangan pemikiran dalam bidang pendidikan, hukum, ekonomi, 
politik, dan agama untuk membuka tabir pemahaman masyarakat dan juga memberikan masukan kepada para pengambil keputusan; (2) sebagai motivator masyarakat, dimana PTAIN diharapkan mampu memberikan sumbangan pemikiran, baik melalui tulisan di mass media, khutbah-khutbah, penataranpenataran, dan sebagainya untuk mendorong masyarakat ber amar ma'ruf nahi munkar; dan (3) sebagai tokoh panutan, dimana civitas akademika PTAIN diharapkan dalam aktivitas dan penampilan keseharian dapat menjadi contoh atau panutan masyarakat dalam berbagai aspek kehidupan.

Dengan peran-peran strategis tersebut, diharapkan PTAIN dapat ikut serta menjadi pemain dalam panggung sejarah kehidupan masa depan. Sebab apalah artinya sebuah kehidupan yang demokratis, kalau tidak dilandasi dengan moral yang kokoh. Dan penjaga moral itu diharapkan datang dan lahir dari PTAIN, bukan sebaliknya. Banyak contoh yang mendukung argumen ini, termasuk menggejalanya berbagai korupsi, kolusi, dan nepotisme di berbagai birokrasi negeri ini, yang dapat kita saksikan bersama. Hal ini terjadi karena birokrasi dibangun tidak berdasarkan etik, moral, dan spiritual yang kokoh, tetapi berdasarkan kepentingan sesaat atau jangka pendek. Andaikan alumni PTAIN banyak yang masuk di berbagai sektor birokrasi tersebut, menurut keyakinan saya, insyaallah krisis multi dimensional ini dapat ditekan seminimal mungkin, tidak terjadi separah seperti yang kita alami ini.

\section{Peluang dan Tantangan Pengembangan PTAIN}

Menurut hemat saya, tantangan utama PTAIN ke depanadalah kualitas sumberdaya manusia. Hal ini terbukti dengan masih sedikitnya tenaga pengajar di PTAN yang bergelar doctor dan professor. Untuk mewujudkan PTAIN yang kompetitif dan unggul era globalisasi adalah dengan menyiapkan sumber daya manusia yang berkualitas adalah sebuah keniscayaan. SDM yang berkualitas, disamping pendidikan dan gelar akademik yang memadai, juga harus ditunjang dengan penguasaan terhadap IPTEKS dan sekaligus mampu mengembangkan IPTEKS untuk meningkatkan kesejahteraan kehidupan masyarakat, bangsa, dan umat manusia pada umumnya. Atau dengan kata lain SDM yang bekualitas adalah yang melek IPTEKS. Tentunya melek IPTEKS yang tetap memegang nilai-nilai moral yang kokoh dan bersendikan nilai ajaran agama.

Tantangan berikutnya adalah menyiapkan manusia unggul. Manusia unggul adalah manusia yang dapat bersaing dan manusia yang berpikir kreatif. Manusia unggul tidak lain daripada manusia yang berkualitas, artinya manusia 
yang dapat mengembangkan potensi yang ada padanya seoptimal mungkin, sehingga dengan potensinya itu dia dapat bersaing dengan manusia lainnya. Dengan potensi yang berkembang itu dia dapat mengadakan pilihan-pilihan yang tepat. Sedang manusia kreatif adalah manusia yang dapat bersaing dan dapat memunculkan kreasi-kreasi baru.

Tantangan lainnya adalah masalah globalisasi. Ada beberapa dampak globalisasi yang harus pula dicermati oleh tenaga pengajar di PTAIN, yaitu: (a) ancaman terhadap budaya bangsa dan nilai-nilai moral agama; (b) lunturnya identitas bangsa; dan (c) lunturnya kesadaran terhadap wawasan nusantara.

Sejalan dengan persoalan tersebut, maka untuk dapat mengatasi berbagai persoalan tersebut, PTAIN harus menyiapkan tenaga pengajar yang handal. Tenaga pengajar yang handal harus mengindikasikan hal-hal sebagai berikut: (1) landasan moral yang kokoh untuk melakukan "jihad" dan mengemban "amanah"; (2) kemampuan mengembangkan jaringan-jaringan kerjasama atau "silaturrahim"; (3) membentuk team work yang kompak; (4) mencintai kualitas yang tinggi, dan (5) produktif dalam menghasilkan karya keilmuan.

Disamping itu, tenaga pengajar PTAIN harus mempunyai sikap: (1) dedikasi dan disiplin dalam melaksanakan pekerjaan, (2) jujur dalam setiap aktifitas kehidupan, (3) inovatif dalam melihat persoalan kekinian yang kurang relevan, (4) tekun dalam menjalankan tugas dan kewajiban, dan (5) ulet dalam menghadapi realitas kehidupan.

Sedang peluangnya, dengan adanya globalisasi dan pasar bebas, semakin terbuka lebar berbagai bidang kerja yang mengandalkan profesionalisme. Sebab orientasi berbagai lapangan kerja di era globalisasi dan pasar bebas akan lebih mengacu pada kualitas unggul. Untuk itu, PTAIN harus berorientasi pada upaya melahirkan sarjana yang betul-betul profesional dibidangnya, sehingga tidak terpaku pada disiplin ilmunya semata atau memasuki sektor informal, tetapi juga bisa masuk kepada semua sektor formal dan non-formal, termasuk sektorsektor moderen.

Dengan berpijak pada pemikiran tersebut, menunjukkan banyak peluang bagi PTAIN dan sekaligus tantangan. Sebagai peluang, kalau PTAIN mampu menghantarkan lulusannya untuk memenangkan persaingan meraih peran-peran strategis. Sebagai tantangan, kalau dia tidak mampu memenangkan persaingan, maka akan menjadi kelompok marginal (pinggiran) dan hanya menjadi penonton dalam panggung sejarah kehidupan.

Kalau yang terakhir ini terjadi, maka pupuslah sudah harapan untuk ikut serta mengisi formasi masyarakat baru, dan kita siap-siap untuk berada di 
halaman belakang rumah kita sendiri, karena halaman depan rumah kita sudah tergadai oleh orang lain. Namun yang perlu diingat bahwa, untuk mencapai semua itu syarat yang harus dipenuhi adalah profesionalisme, intelektualitas, moralitas, dan spiritualitas yang tinggi. Untuk itu, PTAIN harus mampu memberikan bekal kepada lulusannya dengan seperangkat kemampuan, misalnya kemampuan menganalisis situasi social (mengetahui tanda-tanda zaman), berbahasa asing, manajerial, dan ketrampilan praktis, agar dia bisa survival di tengah-tengah maraknya suasana globalisasi.

Sedang peluang PTAN dalam era globalisasi dan pasar bebas adalah semakin terbuka lebarnya untuk mengembangkan diri tanpa harus dihambat oleh berbagai peraturan yang "menyesakkan". Peluang ini, sebagaimana yang terjadi di Amerika Serikat (hasil studi banding), dapat diidentifikasi sebagai berikut: (1) dapat menentukan berbagai kebijakan kampus yang bersifat flexible atau lentur untuk kemudian diintegrasikan oleh para pengajar sesuai dengan kondisi riil masyarakat dan kebutuhan mahasiswa, (2) dapat menentukan tenaga pengajar sendiri sesuai dengan kriteria yang telah ditetapkan, (3) dapat menentukan pengelolaan dana, (4) dapat menjalin kerjasama dengan berbagai pihak, dan (5) dapat mengembangkan program-program non formal yang menyentuh kebutuhan riil masyarakat.

Namun demikian, peluang ini tidak akan memberikan makna yang signifikan kalau tidak didukung dengan kerja keras dan kerja cerdas. Untuk itu, antara peluang dan tantangan ini harus disikapi secara arif dan bijaksana, karena kduanya mempunyai hubungan yang signifikan.

\section{Strategi Pengembangan PTAIN}

Strategi pengembangan PTAIN harus mengacu pada profesionalisme. Karena profesionalisme merupakan syarat penting adanya dinamika pada lembaga pendidikan.

Berkaitan dengan professionalisme ini, Muhaimin (2001) melakukan sintesis mengenaijalan yang terbaik untuk peningkatan dan perbaikan organisasi (termasuk pendidikan) secara terus menerus ber-dasarkan penelitian beberapa pakar pendidikan dan non kependidikan, seperti Covey (1996), Drucker (1992), Senge (1990), Fullan (1993), Hammond (1996), Newman \& Weblage (1995), dan Louis, Kruse \& Raywid (1996) sebagai berikut: (1) Hanyalah organisasi-organisasi atau lembaga-lembaga yang memiliki keinginan besar untuk belajar yang akan berpengaruh secara abadi, (2) Setiap perusahaan (termasuk usaha pendidikan) harus menjadi suatu institusi belajar dan institusi mengajar. Organisasi

Jurnal "El-Harakah" Vol. 5, No. 2, Juli - Oktober 2003 
atau lembaga yang menciptakan suasana belajar secara kontinyu dalam pekerjaannya akan mendominasi abad 21, (3) Perusahaan yang paling sukses di masa depan akan menjadi suatu organisasi belajar, (4) Problem baru dari perubahan ialah tindakan apa yang perlu diambil untuk membuat sistem pendidikan sebagai organisasi belajar, bukan hanya untuk menanggapi kebijakan tetapi juga sebagai cara hidup, (5) Jika lembaga pendidikan ingin mem-pertinggi kapasitas organisasinya untuk meningkatkan belajar peserta didik, mereka hendaknya bekerja atas bangunan suatu masyarakat yang profesional, yang bercirikan: adanya kesamaan tujuan, keinginan kolaboratif, dan tanggungjawab kolektif di antara staf, dan (6) Bagaimanapun pembaharuan lembaga pendidikan harus diarahkan pada upaya terwujudnya masyarakat belajar yang profesional.

Untuk mewujudkan semua itu, maka PTAIN masa kini dan masa depan harus dikelola dengan manajemen moderen, yang sekarang ini dikenal dengan istilah Total Quality Education (TQE) sebagai adaptasi dari Total Quality Management (TQM).

TQE adalah suatu pendekatan dalam menjalankan aktifitas pendidikan yang mencoba untuk memaksimumkan daya saing (competitiveness) lembaga pendidikan melalui perbaikan secara terus menerus atas lulusan, pelayanan, proses, dan lingkungannya.

Dalam melaksanakan TQE, ada 10 prinsip utama yang harus menjadi perhatian, yaitu: (1) kepuasan pada konsumen (mahasiswa, wali, dan masyarakat), (2) obsesi terhadap kualitas, (3) pendekatan ilmiah, (4) komitmen jangka panjang, (5) kerjasama tim, (6) perbaikan sistem secara berkesinambungan, (7) pendidikan dan pelatihan, (8) kebebasan yang terkendali, (9) kesatuan tujuan antar berbagai unsur, (10) adanya keterlibatan dan pemberdayaan karyawan (Tribus, 1999).

Disamping itu, PTAIN harus dapat menjadi center of learning society. Artinya mampu menjadi perekat masyarakat dalam melaksanakan aktifitas pendidikan. Hal ini sebagai bentuk antisipasi kecenderungan masyarakat masa depan, yang gandrung akan pendidikan. Tetapi bukan pendidikan formal dan reguler, namun pendidikan yang "membebaskan" yang mampu memberikan bekal wawasan dan informasi yang aktual dan pragmatis. Untuk itu, PTAIN harus mampu melahirkan program dan produk yang bisa "dijual", agar PTAIN selalu menjadi tumpuan masyarakat yang ingin belajar.

Berkaitan dengan kegiatan pendidikan dan pembelajaran, agar PTAIN mendapat simpati dan menjadi pilihan umat, maka harus mampu menghasilkan lulusan yang berkualitas. Lulusan yang berkualitas harus mencerminkan karakter 
sebagai berikut: (a) akhlakul karimah; (b) mandiri, jujur, disiplin, dan bertanggungjawab; (c) tidak pamrih; (d) cinta ilmu; (e) kritis dan suka bekerja keras. Juga yang tidak kalah pentingnya adalah, PTAIN dalam menyongsong era globalisasi dan pasar bebas harus prospektif, atau mampu memenuhi tiga harapan masyarakat, yaitu mencerdaskan; menjanjikan, dan menginternalisasikan.

Mencerdaskan maksudnya, mampu memberikan bekal kepada peserta didik ketrampilan berfikir secara kritis, analitis, progresif, inovatif, dan futuristik. Menjanjikan maksudnya, PTAIN harus mampu memberikanjaminan akan lulusannya untuk berprestasi bagus dan rampil dalam memasuki sektorsektor riil di masyarakat. Menginternalisasikan maksudnya, PTAIN mampu memberikan seperangkat nilai kepada mahasiswa, agar mereka mampu mengambil pilihan-pilihan etik sesuai dengan nuraninya berdasarkan kerangka normatif agama.

\section{E. Penutup}

Globalisasi dan pasar bebeas, bagi PTAIN bisa jadi sebagai peluang sekaligus tantangan. Namun demikian, apapun resikonya pengembangan PTAIN harus tetap berjalan seiring dengan semangat otonomi dan globalisasi. Sebab otonomi dan globalisasi adalah sebuah keniscayaan yang mesti hadir dalam ruang kehidupan berbangsa dan bernegara kita. Untuk itu, harus dihadapi dengan sikap optimis dan strategis serta antisipatif terhadap "tanda-tanda jaman". Apabila PTAIN mampu melakukan ini, tidak mustahil PTAINI akan dapat bersaing dengan lembaga lain yang pada akhirnya akan menjadi pilihan umat. Indikasi pragmatisnya, setiap tahun jumlah pendaftar semakin meningkat secara signifikan dan lulusan yangdihasilkan dapat memasuki peluang-peluang kerja serta menjadi panutan di masyarakat.

Bagi UIN Malang, saya melihat bahwa lembaga ini sekarang mempunyai potensi sumber daya manusia yang dapat dibanggakan. Untuk itu, bagaimana mengelola potensi ini menjadi energi yang mampu membangkitkan semangat bekerja dan berkarya, sehingga mampu melahirkan karya-karya ilmiah yang fenomenal dan monumental, yang dapat menjadi rujukan bagi UIN, IAIN dan STAIN di Indonesia. Dengan ini diharapkan, UIN Malang ke depan akan menjadi lembaga alternatif, di samping UIN Jakarta dan UIN Yogyakarta. Semoga. 


\section{DAFTAR PUSTAKA}

Abdillah, M. (1997). Menimbang Kurikulum 1997. Dalam Perta, Jurnal Komunikasi Perguruan Tinggi Islam. Vol. 1, No. 1, September 1997, (14-23).

Achmad, A. (1991). Kerangka Masalah Perguruan Tinggi Islam: Sebuah Ikhtiar Pola Alternatif. Dalam Usa, M. (Ed.). Pendidikan Islam di Indonesia: Antara Cita dan Fakta. Yogyakarta: Tiara wacana.

Ghofir, A. (1993). Wawasan Keilmuan Perguruan Tinggi (IAIN). Malang: FT IAIN Sunan Ampel.

Ghofir, A. (2001). Laporan Individual: Hasil Studi Banding "Educational Lea-dership and Policy Development, AMERICAN PRINCIPLES-INDONESIAN PRACTICES, June, 4-15, 2001.

Hasibuan, H.S. (1998). Kiprah Alumni IAIN Dalam Pembangunan. Dalam Harahap (Ed.). Perguruan Tinggi Islam Di Era Globalisasi. Yogyakarta: Tỉara Wacana \& IAIN Sumut.

Lewis, R.G. \& Smith, D.H. (1994). Total Quality in Higher Education. Delray Beach: St. Lucie Press.

Muhaimin, Y. (1999). Kebijaksanaan Pendidikan Nasional dalam Kait annya dengan Otonomi Daerah. Dalam PERTA, Jurnal Komunikasi Perguruan Tinggi Islam. Vol. III, No.1, 2000, hal. 6-10.

Muhaimin (2001). Pengembangan Masyarakat Belajar yang Profesional, Menyambut Otonomi Daerah. Dalam MPA, 174 (XV), Maret 2001, 32-35.

PERTA, Jurnal Komunikasi Perguruan Tinggi Islam. Vol. III, No.1, 2000, hal. 3-5.

Rahardjo, M.D. (1992). Intelektual, Intelegensia, dan Perilaku Politik Bangsa, Risalah Cendekiawan Muslim. Bandung: Mizan.

Taher, T. (1997). IAN/STAN: Kompetisi Menuju Center of Excelence. Dalam Perta, Jurnal Komunikasi Perguruan Tinggi Islam. Vol. 1, No. 1, September 1997, (49-53).

Tilaar, H.A.R. (1998). Beberapa Agenda Reformasi Pendidikan Nasional, Dalam Perspektif Abad 21. Magelang: Tera Indonesia.

Tribus, M. (1999). Quality Management in Education. Hayward, CA: Exergy, Inc.

*) Penulis adalah Dosen Tetap Fak. Tarbiyah UIN Malang 